\title{
EROSIVIDADE DAS CHUVAS E SUA DISTRIBUIÇÃO ENTRE 1989 E 1998 NO MUNICÍPIO DE LAGES (SC)
}

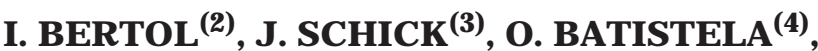 \\ D. LEITE ${ }^{(4)}$, D. VISENTIN ${ }^{(4)} \&$ N. P. COGO(5)
}

\begin{abstract}
RESUMO
A erosão hídrica resulta da erosividade das chuvas e da erodibilidade dos solos. O conhecimento da erosividade, portanto, torna-se um guia valioso na recomendação de práticas de manejo e conservação do solo que visem à redução da erosão hídrica. $O$ objetivo do trabalho foi identificar e quantificar o fator de erosividade das chuvas naturais de Lages (SC), bem como conhecer sua distribuição temporal. A pesquisa foi realizada em 2000, utilizando dados de chuvas e perdas de solo do período entre 1989 e 1998, no Centro de Ciências Agroveterinárias de Lages (SC), situado a $27^{\circ} 49^{\prime}$ de latitude Sul e $50^{\circ} 20^{\prime}$ de longitude Oeste, a 937 m de altitude média, na região do Planalto Sul Catarinense. Foram estudados diversos fatores de erosividade, utilizando os métodos de Wischmeier \& Smith e de Wagner \& Massambani, de 437 chuvas erosivas, num total de 966 chuvas, compreendendo um volume médio anual de $1.301 \mathrm{~mm}$ de chuvas erosivas, num total médio anual de $1.549 \mathrm{~mm}$ de chuvas. $\mathrm{O} \mathrm{El}_{30}$ é o fator de erosividade (fator R da Equação Universal de Perda de Solo - EUPS) recomendado para Lages, cujo valor médio anual é de $5.790 \mathrm{MJ} \mathrm{mm} \mathrm{ha}^{-1} \mathrm{~h}^{-1} ; 63 \%$ do qual ocorre na primavera-verão; 76 \% no período de setembro a março e, no período crítico, outubro, janeiro e fevereiro, $41 \%$ do referido fator. Considerando o número e o volume das chuvas, 45 e 84 \%, respectivamente, são erosivas.
\end{abstract}

Termos de indexação: fator $\mathbf{R}$, fator $\mathrm{EI}_{30}$, energia cinética, chuva erosiva, EUPS.

SUMMARY: RAIN EROSIVITY AND ITS DISTRIBUTION BETWEEN 1989 AND 1998 IN THE DISTRICT OF LAGES, STATE OF SANTA CATARINA, BRAZIL

Water/ Hydro-erosion comes as a result of rain erosivity and soil erodibility. Knowledge on erosivity is ther efore useful as a guide for recommendations on management practices

\footnotetext{
(1) Parte da Tese de M estrado do segundo autor, executado com recursos da UDESC e CNPq, apresentada na II RNRS/SBCS, Santa Maria (RS). Recebido para publicação em janeiro de 2001 e aprovado em outubro de 2001.

(2) Professor do Departamento de Sol os do Centro de Ciências Agroveterinárias, Universidade do Estado de Santa Catarina - UDESC. Caixa Postal 281, CEP 88520-000 Lages (SC). Bolsista do CNPq. Email: a2ib@cav.udesc.br.

(3) Engenheiro-Agrônomo, MSc., CAV/UDESC.

(4) Bolsista de Iniciação Científica do Curso de Agronomia do CAV/UDESC.

(5) Professor do Departamento de Solos, Universidade Federal do Rio Grande do Sul - UFRGS. Caixa Postal 776, CEP 90001-970 Porto Alegre (RS). Bolsista do CNPq.
} 
and soil conservation which havetheaim to reduce hydro- erosion. Objectives of this study were the factor identification and quantification of natural rain erosivity in Lages, Santa Catarina, as well as knowledgeon its temporary distribution. Thestudy was carried out in 2000, using data on rainfall and soil loss of the period from 1989 to 1998, in the Centro de Ciências Agroveterinárias of Lages (SC), at $27^{\circ} 49^{\prime}$ latitude south and $50^{\circ} 20^{\prime}$ longitude West, at an average height of $937 \mathrm{~m}$ in the southern plateau region of Santa Catarina. Several erosivity factors were examined in 437 erosi verainfalls out of a total of 966, making up an average annual volume of 1,301 mm erosive rainfalls in a total annual average of $1,549 \mathrm{~mm}$ rain, using theWischmeier \& Smith as wel as theWagner \& Massambi methods. $\mathrm{EI}_{30}$ (factor $\mathrm{R}$ of the Universal Soil Loss E quation of -USLE) is the recommended erosivity factor, whoseaverageannual valueis 5,790 MJ mm ha-1 $\mathrm{h}^{-1}$, out of which $63 \%$ occur during spring and summer, $76 \%$ in the period from September to March, and, during the critical period of October, J anuary and F ebruary, $41 \%$ of thefactor referred to. Considering number and volume of the rainfalls, 45 and $84 \%$, respectively, are erosive.

Index terms: Factor $\mathrm{R}$, factor $\mathrm{EI}_{30}$, kinetic energy, erosiverainfall, USLE.

\section{NTRODUÇÃO}

A erosão hídrica é o resultado da ação do impacto das gotas da chuva e do escoamento superficial combinados com a erodi bilidade do solo, caracterizada pelas fases de desagregação, transporte e deposição. A desagregação e o transporte são principalmente provocados pelo impacto das gotas de chuva e escoamento superficial, respectivamente, sobre a superfície do solo (Hudson, 1981). O fator R, que significa a erosividade, é um valor numérico que representa o potencial da chuva e escoamento superficial para proporcionar erosão hídrica em uma área descoberta, sendovariável com as características e, portanto, com a variabilidade espacial etemporal das chuvas (Wischmeier \& Smith, 1978). Assim, nas regiões do globo terrestre, onde o clima varia expressivamente de uma estação climática para outra, é provável que a erosividade também varie.

Em regiões temperadas, como nos EUA, os coeficientes de correlação entre os fatores de erosividade $\mathrm{EI}_{30}$ e as perdas de solo variam de 0,84 a 0,98 (Wischmeier, 1959), indicando ser este fator um bom preditor da erosão hídrica para essas regiões.

No Brasil, os coeficientes de correlação entre os fatores de erosividade das chuvas eas perdas de solo têm variado de 0,57 a 0,81. Dentre os diferentes fatores de erosividade estudados, o $\mathrm{EI}_{30}$ tem-se mostrado um bom preditor, já que o coeficiente de correlação entre ele e as perdas de solo, em geral, não tem diferido dos demais (Lombardi N eto, 1977; Biscaia et al., 1981; M orais et al., 1988; Carval ho et al., 1997; Silva et al., 1997; Al buquerque et al., 1998; Schick, 1999; Beutler, 2000).

Em regiões tropicais e subtropicais, no entanto, outros fatores têm demonstrado mel hor correlação com as perdas de solo (Lal et al., 1980). Para a África do Sul, por exemplo, Hudson (1981), analisando o fator KE > 25, o qual é representado pel o somatório da energia cinética total das chuvas com intensidade superior a $25 \mathrm{~mm} \mathrm{~h}^{-1}$, encontrou coeficientes de correlação entre este fator e as perdas de solo variando de 0,92 a 0,96. Isto se deve ao fato de, nessas regiões, as chuvas apresentarem menor duração e maiores intensidade e erosividade do que as de regiões temperadas.

Margolis et al. (1985) obtiveram o valor de $\mathrm{EI}_{30}$ médio anual de2.100 MJ mm ha-1 $\mathrm{h}^{-1}$, para Caruaru (PE); Rufino (1986), para 32 localidades do estado do Paraná, obteve valores médios anuais de $\mathrm{EI}_{30}$ variando de 5.275 a $12.559 \mathrm{MJ} \mathrm{mm} \mathrm{ha-1} \mathrm{h}^{-1}$, enquanto Carvalhoet al . (1989) encontraram erosividademédia anual de $7.747 \mathrm{MJ} \mathrm{mm} \mathrm{ha}^{-1} \mathrm{~h}^{-1}$, para Mococa (SP). Bertol (1993) eBertol (1994) obtiveram val ores médios anuais de $\mathrm{EI}_{30}$ de 5.694 e $6.329 \mathrm{MJ} \mathrm{mm} \mathrm{ha-1} \mathrm{h}^{-1}$, para Lages e Campos Novos (SC), respectivamente, enquanto Silva et al. (1997) encontraram val or médio anual de $8.355 \mathrm{MJ} \mathrm{mm} \mathrm{ha}^{-1} \mathrm{~h}^{-1}$, para Goiânia (GO). Schick (1999), para Lages (SC), eB eutler (2000), para Chapecó (SC), encontraram valores médios anuais

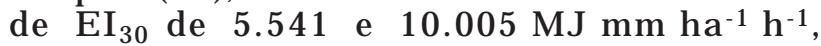
respectivamente, sendo essefator aproximadamente duas vezes maior na primavera-verão do que no outono-inverno, nesses locais.

O objetivo do trabal ho foi quantificar o númeroe o volume das chuvas erosivas, chuvas não-erosivas e totais de chuvas, selecionar o fator de erosividade médio anual (fator R da EUPS), quantificar eestudar a distribuição do referido fator, tanto anual quanto mensalmente, para as chuvas naturais de Lages (SC), no período de 1989 a 1998.

\section{MATERIAL E MÉTODOS}

A pesquisa foi desenvolvida noCentrodeCiências Agroveterinárias (CAV/UDESC) de Lages (SC), no 
período de 1989 a 1998, com um intervalo de um ano (1992), ano em que não foram coletados dados de perda de sol o do experimento. Os dados dechuva e de perda de solo foram obtidos na Estação Meteorológica e no experimento de erosão hídrica, localizados no Centro de Ciências Agroveterinárias de Lages (SC), a $27^{\circ} 49^{\prime}$ latitudeSul e $50^{\circ} 20^{\prime}$ longitude Oeste de Greenwich. A altitude média de Lages é de 953 m, com temperatura, máxima e mínima, média anual de 21,7 e $11,5^{\circ} \mathrm{C}$, respectivamente. Segundo Köepen, o clima da região é do tipo Cfb.

A erosividade foi obtida para 437 eventos de chuva registrados em pluviogramas diários modelo $\mathrm{IH}-01-01$. Os pluviogramas apresentavam amplitude de registro de $10 \mathrm{~mm}$ de precipitação e de $24 \mathrm{~h}$ de duração, com unidades de 0,1 mm, para o volume, e de $10 \mathrm{~min}$, para o tempo.

A pós as chuvas terem sido cotadas manualmente em segmentos de intensi dade uniforme, calculou-se sua energia cinética por $\mathrm{mm}$ de chuva com auxílio de programa computacional (Cataneo et al., 1982), com base no método de Wischmeier \& Smith (1958) e com uma modificação feita no referido programa por Maria (1994), pelo método de Wagner \& Massambani (1988), conforme as equações:

$$
\begin{aligned}
& E C=0,119+0,0873 \log _{10} I \quad \text { (Wischmeier } \\
& \text { \& Smith, 1958) } \\
& \text { Ew }=0,153+0,0645 \log _{10} \text { I (Wagner \& } \\
& \text { Massambani, 1988) }
\end{aligned}
$$

sendo

Ec e Ew = energia cinética por $\mathrm{mm}$ de chuva, MJ ha-1 $\mathrm{mm}^{-1}$

$\mathrm{I}$ =intensidade da chuva, $\mathrm{mm} \mathrm{h}^{-1} \mathrm{e}$

0,119; 0,0873; 0,153 e 0,0645, parâmetros de ajuste das equações.

As equações 1 e 2 são apli cáveis para intensidades de chuvas com até $76 \mathrm{~mm} \mathrm{~h}^{-1}$. Acima desse limite de intensidade, a energia cinética por milímetro de chuva é constante, sendo de 0,2832 MJ ha-1 $\mathrm{mm}^{-1}$, para a equação 1 (Wischmeier \& Smith, 1958), e de 0,2743 , para a equação 2 (Wagner $\&$ Massambani, 1988).

Em ambos os métodos, as unidades inglesas foram convertidas para o Sistema Internacional de Unidades, conformesugerido por Foster et al. (1981).

As chuvas foram consideradas erosivas quando apresentavam dez milímetros ou mais, ou quando apresentavam o mínimo de seis milímetros precipitados em um período máximo de $15 \mathrm{~m}$, tendo sido as demais consideradas não-erosivas (Wischmeier $\&$ Smith, 1978).

O produto da energia cinética total das chuvas (E), MJ ha-1, pela sua intensidade máxima (I ) em 5 , $10,15,20,25,30,35,40,45,50,55$ e $60 \mathrm{~min}^{\mathrm{mm} \mathrm{h}} \mathrm{m}^{-1}$, forneceu, para cada chuva, os fatores de erosividade
$\mathrm{EI}_{5}, \mathrm{EI}_{10}, \mathrm{EI}_{15}, \mathrm{EI}_{20}, \mathrm{EI}_{25}, \mathrm{El}_{30}, \mathrm{EI}_{35}, \mathrm{El}_{40}, \mathrm{EI}_{45}, \mathrm{El}_{50}$ $\mathrm{EI}_{55} \mathrm{e} \mathrm{El}_{60}, \mathrm{MJ} \mathrm{mm} \mathrm{ha}^{-1} \mathrm{~h}^{-1}$, para cada um dos métodos estudados. O fator mensal foi obtido pelo somatório dos fatores de erosividade de cada chuva ocorrida ao longo do referido mês, e o fator anual, a partir do somatório dos fatores mensais.

A curva de distribuição relativa da erosividade acumulada no ano foi obtida, para o $\mathrm{EI}_{30}$, por meio dos valores médios mensais do fator de erosividade acumulados durante o ano, conforme Wischmeier \& Smith (1978). Foram obtidos, ainda, os fatores de erosividade KE $>25$ e KE $>10$, $\mathrm{MJ} \mathrm{ha}^{-1}$, pelo somatório das energias cinéticas dos segmentos de chuva com intensidades maiores do que 25 e $10 \mathrm{~mm} \mathrm{~h}^{-1}$, respectivamente, conforme sugerido por Hudson (1981). O volume médio anual de chuva $(\mathrm{mm})$ foi considerado um fator de erosividade, também correlacionado com as perdas de solo.

Em parcelas de 3,5 x 22,1 m, em duas repetições, del imitadas por chapas galvanizadas, nas laterais e na extremidade superior, e por cal has coletoras de enxurrada, na extremidade inferior, conectadas por canos de PVC a tanques col etores com divisores de vazão com nove janelas, localizados $6,0 \mathrm{~m}$ abaixo, foram coletadas e quantificadas as perdas de solo em cada evento de chuva er osiva, conforme o método descrito em Cogo (1978).

Durante o experimento, as parcelas foram preparadas duas vezes por ano, com uma aração e duas gradagens no sentido paral el o ao dedive: uma vez antecedendo a cultura de primavera-verão e a outra de outono-inverno. O solo das parcelas foi mantido livre de vegetação e crosta superficial durante o período experimental, por meio de dessecantes químicos e capinas ou escarificações manuais.

Os dados de perda de sol o foram ajustados para a declividade-padrão da EUPS, ou seja, 0,09 $\mathrm{m} \mathrm{m}^{-1}$, por meio do fator grau de dedive, conforme proposto por Wischmeier \& Smith (1978), utilizando a equação:

$$
S=0,065+4,56 \operatorname{sen} \theta+65,41(\operatorname{sen} \theta)^{2}
$$

sendo

$\mathrm{S}=$ fator grau do declive e

$\theta=$ ângulo do declive.

Foi efetuada regressão linear simples entre as perdas de sol o obtidas na parcela-padrão da EUPS e os diversos fatores de erosividade calculados, utilizando o modelo:

$$
\mathrm{Y}=\mathrm{a}+\mathrm{bX}
$$

sendo

$\mathrm{Y}=$ perda de solo estimada $\mathrm{Mg} \mathrm{ha}^{-1}$,

$X=$ fator erosividade (unidade variável dependendo do fator) $\mathrm{e}$

$a, b=$ constantes de ajuste do modelo. 
A homogeneidade dos coeficientes de correlação ( $r)$, resultantes da regressão linear simples entreas perdas de solo e os diversos fatores de erosividade, foi testada utilizando o método proposto por Graybill (1961), tendo sido os coeficientes de correlaçãotestados dois a dois pelo método de Steel \& Torrie (1960).

\section{RESULTADOS E DISCUSSÃO}

\section{Número e volume das chuvas}

Durante o período experimental, ocorreram 966 chuvas, das quais $45 \%$ foram erosivas e $55 \%$ não-erosivas (Quadro 1). Resultados semel hantes foram obtidos por Bertol (1993) eBertol (1994). O mês de fevereiro destacou-se com $12 \%$ do número total de chuvas, enquanto, nos meses de abril, maio, junho, jul ho e agosto, ocorreram chuvas em menor número, com aproximadamente $30 \%$ delas. Em relação ao número de chuvas erosivas, os meses de outubro, janeiro e fevereiro contribuíram com $36 \%$, caracterizando-se como meses críticos, nos quais se pode esperar maior risco de erosão, pel o fato de os meses de setembro e outubro coincidirem com o preparo e semeadura das culturas de primavera-verão e com o início do seu desenvolvimento, enquanto, no mês de maio, ocorreu apenas $4 \%$ desse volume.

Quadro 1. Valores mensais, anuais e médios mensais e anual dos números de chuvas erosivas, nãoerosivas e total, observadas no período de 1989 a 1998 em Lages (SC)

\begin{tabular}{|c|c|c|c|c|c|c|c|c|c|c|c|c|c|}
\hline Ano & J an. & Fev. & Mar. & Abr. & Maio & J un. & J ul. & Ago. & Set. & Out. & Nov. & Dez. & Total \\
\hline \multicolumn{14}{|c|}{ Erosivas } \\
\hline $\begin{array}{l}1989 \\
1990 \\
1991 \\
1993 \\
1994 \\
1995 \\
1996 \\
1997 \\
1998\end{array}$ & $\begin{array}{r}9 \\
8 \\
3 \\
6 \\
2 \\
3 \\
10 \\
7 \\
5\end{array}$ & $\begin{array}{r}2 \\
5 \\
0 \\
6 \\
11 \\
7 \\
7 \\
7 \\
9\end{array}$ & $\begin{array}{l}4 \\
5 \\
3 \\
4 \\
3 \\
1 \\
4 \\
2 \\
7\end{array}$ & $\begin{array}{l}3 \\
4 \\
2 \\
3 \\
4 \\
2 \\
2 \\
0 \\
5\end{array}$ & $\begin{array}{l}3 \\
3 \\
3 \\
2 \\
4 \\
0 \\
0 \\
2 \\
1\end{array}$ & $\begin{array}{l}1 \\
4 \\
3 \\
2 \\
3 \\
6 \\
4 \\
3 \\
2\end{array}$ & $\begin{array}{l}4 \\
4 \\
2 \\
4 \\
5 \\
3 \\
5 \\
6 \\
6\end{array}$ & $\begin{array}{l}5 \\
3 \\
3 \\
1 \\
0 \\
3 \\
4 \\
3 \\
8\end{array}$ & $\begin{array}{l}5 \\
7 \\
3 \\
6 \\
3 \\
4 \\
5 \\
3 \\
6\end{array}$ & $\begin{array}{l}4 \\
9 \\
6 \\
3 \\
6 \\
6 \\
3 \\
8 \\
4\end{array}$ & $\begin{array}{l}2 \\
6 \\
6 \\
5 \\
6 \\
2 \\
2 \\
7 \\
1\end{array}$ & $\begin{array}{l}3 \\
4 \\
6 \\
0 \\
1 \\
4 \\
3 \\
4 \\
4\end{array}$ & $\begin{array}{l}45 \\
62 \\
40 \\
42 \\
48 \\
41 \\
49 \\
52 \\
58\end{array}$ \\
\hline Média & 5,9 & 6,0 & 3,7 & 2,8 & 2,0 & 3,1 & 4,3 & 3,3 & 4,7 & 5,4 & 4,1 & 3,2 & 48,5 \\
\hline Total & 53 & 54 & 33 & 25 & 18 & 28 & 39 & 30 & 42 & 49 & 37 & 29 & 437 \\
\hline C.V. (\%) & 46 & 53 & 44 & 51 & 68 & 44 & 29 & 65 & 31 & 37 & 53 & 53 & 15 \\
\hline \multicolumn{14}{|c|}{ Não-erosivas } \\
\hline $\begin{array}{l}1989 \\
1990 \\
1991 \\
1993 \\
1994 \\
1995 \\
1996 \\
1997 \\
1998\end{array}$ & $\begin{array}{r}8 \\
11 \\
8 \\
5 \\
0 \\
6 \\
6 \\
7 \\
7\end{array}$ & $\begin{array}{r}6 \\
6 \\
5 \\
8 \\
12 \\
7 \\
7 \\
9 \\
5\end{array}$ & $\begin{array}{l}8 \\
6 \\
2 \\
8 \\
6 \\
8 \\
8 \\
6 \\
4\end{array}$ & $\begin{array}{l}4 \\
5 \\
4 \\
7 \\
1 \\
2 \\
3 \\
6 \\
6\end{array}$ & $\begin{array}{l}1 \\
4 \\
3 \\
2 \\
8 \\
3 \\
1 \\
3 \\
2\end{array}$ & $\begin{array}{l}6 \\
3 \\
8 \\
4 \\
2 \\
5 \\
3 \\
2 \\
2\end{array}$ & $\begin{array}{l}8 \\
4 \\
2 \\
4 \\
3 \\
2 \\
0 \\
2 \\
2\end{array}$ & $\begin{array}{l}3 \\
0 \\
9 \\
2 \\
5 \\
3 \\
3 \\
1 \\
3\end{array}$ & $\begin{array}{l}7 \\
5 \\
5 \\
4 \\
5 \\
5 \\
5 \\
3 \\
3\end{array}$ & $\begin{array}{l}4 \\
6 \\
7 \\
5 \\
4 \\
3 \\
7 \\
6 \\
5\end{array}$ & $\begin{array}{r}6 \\
12 \\
7 \\
2 \\
4 \\
6 \\
7 \\
6 \\
6\end{array}$ & $\begin{array}{r}5 \\
5 \\
7 \\
0 \\
4 \\
3 \\
10 \\
9 \\
6\end{array}$ & $\begin{array}{l}66 \\
67 \\
67 \\
51 \\
54 \\
53 \\
60 \\
60 \\
51\end{array}$ \\
\hline Média & 6,4 & 7,2 & 6,2 & 4,2 & 3,0 & 3,9 & 3,0 & 3,2 & 4,7 & 5,2 & 6,2 & 5,4 & 58,8 \\
\hline Total & 58 & 65 & 56 & 38 & 27 & 35 & 27 & 29 & 42 & 47 & 56 & 49 & 529 \\
\hline C.V. (\%) & 42 & 29 & 32 & 45 & 67 & 50 & 70 & 76 & 25 & 25 & 41 & 53 & 11 \\
\hline \multicolumn{14}{|c|}{ Total } \\
\hline $\begin{array}{l}1989 \\
1990 \\
1991 \\
1993 \\
1994 \\
1995 \\
1996 \\
1997 \\
1998\end{array}$ & $\begin{array}{r}17 \\
19 \\
11 \\
11 \\
2 \\
9 \\
16 \\
14 \\
12\end{array}$ & $\begin{array}{r}8 \\
11 \\
5 \\
14 \\
23 \\
14 \\
14 \\
16 \\
14\end{array}$ & $\begin{array}{r}12 \\
11 \\
5 \\
12 \\
9 \\
9 \\
12 \\
8 \\
11\end{array}$ & $\begin{array}{r}7 \\
9 \\
6 \\
10 \\
5 \\
4 \\
5 \\
6 \\
11\end{array}$ & $\begin{array}{r}4 \\
7 \\
6 \\
4 \\
12 \\
3 \\
1 \\
5 \\
3\end{array}$ & $\begin{array}{r}7 \\
7 \\
11 \\
6 \\
5 \\
11 \\
7 \\
5 \\
4\end{array}$ & $\begin{array}{r}12 \\
8 \\
4 \\
8 \\
8 \\
5 \\
5 \\
8 \\
8\end{array}$ & $\begin{array}{r}8 \\
3 \\
12 \\
3 \\
5 \\
6 \\
7 \\
4 \\
11\end{array}$ & $\begin{array}{r}12 \\
12 \\
8 \\
10 \\
8 \\
9 \\
10 \\
6 \\
9\end{array}$ & $\begin{array}{r}8 \\
15 \\
13 \\
8 \\
10 \\
9 \\
10 \\
14 \\
9\end{array}$ & $\begin{array}{r}8 \\
18 \\
13 \\
7 \\
10 \\
8 \\
9 \\
13 \\
7\end{array}$ & $\begin{array}{r}8 \\
9 \\
13 \\
0 \\
5 \\
7 \\
13 \\
13 \\
10\end{array}$ & $\begin{array}{r}111 \\
129 \\
107 \\
93 \\
102 \\
94 \\
109 \\
112 \\
109\end{array}$ \\
\hline Média & 12,3 & 13,2 & 9,9 & 7,0 & 5,0 & 7,0 & 7,3 & 6,5 & 9,3 & 10,6 & 10,3 & 8,6 & 107,3 \\
\hline Total & 111 & 119 & 89 & 63 & 45 & 63 & 66 & 59 & 84 & 96 & 93 & 78 & 966 \\
\hline C.V. (\%) & 39 & 36 & 23 & 33 & 60 & 34 & 31 & 47 & 20 & 23 & 34 & 47 & 9 \\
\hline
\end{tabular}


Em relação ao volume, as chuvas erosivas corresponderam a $84 \%$ do total precipitado, enquanto as não-erosivas representaram $16 \%$ (Quadro 2), concordando com resultados de vários trabalhos (Eltz, 1977; Saraiva, 1978; J esus Filho, 1987; Bertol , 1993; 1994; Schwarz, 1997; Schick, 1999; Beutler, 2000). O el evado percentual do volume de chuvas erosivas em relação ao total indica a necessidade de preocupação com o uso de práticas conservacionistas na região.
Considerando o volume de chuvas erosivas, verifica-se que os meses de janeiro, fevereiro, julho, setembro e outubro contribuíram com aproximadamente $52 \%$ desse volume. Isso indica que, nesses meses, a preocupação com práticas conservacionistas deveser redobrada na região, especial mente porque em setembro e outubro é efetuado o preparo do solo nos preparos convencionais e semeadura das culturas de primavera-verão, estando o solo sujeito à erosão hídrica, mesmo na semeadura direta, no

Quadro 2. Valores mensais, anuais e médios mensais e anual dos volumes de chuvas erosivas, não-erosivas e total, observadas no período de 1989 a 1998 em Lages (SC)

Ano J an. Fev. Mar. Abr. Maio Jun. Jul. Ago. Set. Out. Nov. Dez. Total

\begin{tabular}{|c|c|c|c|c|c|c|c|c|c|c|c|c|c|}
\hline \multicolumn{14}{|c|}{ Erosivas } \\
\hline 1989 & 216 & 39 & 75 & 94 & 179 & 18 & 57 & 137 & 239 & 95 & 31 & 69 & 1.249 \\
\hline 1990 & 139 & 105 & 107 & 108 & 212 & 147 & 103 & 83 & 171 & 274 & 225 & 90 & 1.764 \\
\hline 1991 & 98 & 0 & 47 & 72 & 63 & 114 & 68 & 52 & 52 & 223 & 72 & 193 & 1.054 \\
\hline 1993 & 135 & 118 & 79 & 48 & 31 & 36 & 281 & 9 & 140 & 82 & 84 & 0 & 1.043 \\
\hline 1994 & 52 & 263 & 60 & 136 & 111 & 74 & 162 & 0 & 49 & 164 & 115 & 58 & 1.245 \\
\hline 1995 & 33 & 134 & 12 & 26 & 0 & 128 & 47 & 50 & 95 & 117 & 26 & 120 & .788 \\
\hline 1996 & 250 & 109 & 122 & 48 & 0 & 136 & 118 & 172 & 101 & 36 & 42 & 73 & 1.207 \\
\hline 1997 & 364 & 141 & 24 & 0 & 50 & 106 & 135 & 129 & 133 & 267 & 187 & 104 & 1.640 \\
\hline 1998 & 97 & 243 & 174 & 233 & 101 & 69 & 134 & 184 & 221 & 96 & 24 & 143 & 1.719 \\
\hline Média & 153,8 & 128,0 & 77,8 & 85,0 & 83,0 & 92,0 & 122,8 & 90,7 & 133,4 & 150,4 & 89,6 & 94,4 & 1.301 \\
\hline Total & 1.384 & 1.152 & 700 & 765 & 747 & 828 & 1.105 & 816 & 1.201 & 1.354 & 806 & 850 & 11.709 \\
\hline C.V. (\%) & 65 & 62 & 61 & 77 & 85 & 46 & 55 & 71 & 48 & 54 & 77 & 55 & 24 \\
\hline \multicolumn{14}{|c|}{ Não-erosivas } \\
\hline 1989 & 38 & 19 & 38 & 25 & 5 & 9 & 28 & 18 & 18 & 18 & 41 & 13 & 270 \\
\hline 1990 & 46 & 28 & 44 & 21 & 15 & 23 & 22 & 0 & 33 & 29 & 47 & 14 & 322 \\
\hline 1991 & 24 & 10 & 3 & 22 & 2 & 37 & 4 & 34 & 12 & 22 & 33 & 29 & 232 \\
\hline 1993 & 22 & 38 & 26 & 32 & 9 & 19 & 20 & 9 & 11 & 21 & 5 & 0 & 212 \\
\hline 1994 & 0 & 58 & 29 & 4 & 35 & 9 & 17 & 20 & 22 & 15 & 6 & 12 & 228 \\
\hline 1995 & 24 & 28 & 31 & 6 & 13 & 16 & 5 & 17 & 24 & 13 & 25 & 15 & 218 \\
\hline 1996 & 41 & 35 & 38 & 15 & 9 & 8 & 0 & 21 & 27 & 32 & 31 & 46 & 303 \\
\hline 1997 & 25 & 42 & 19 & 26 & 13 & 2 & 8 & 1 & 3 & 22 & 19 & 46 & 226 \\
\hline 1998 & 28 & 17 & 16 & 24 & 11 & 11 & 11 & 19 & 17 & 22 & 19 & 16 & 211 \\
\hline Média & 27,6 & 30,6 & 27,1 & 19,4 & 12,4 & 14,9 & 12,8 & 15,4 & 18,6 & 21,6 & 25,1 & 21,2 & 247 \\
\hline Total & 248 & 275 & 244 & 175 & 112 & 134 & 115 & 139 & 167 & 194 & 226 & 191 & 2.223 \\
\hline C.V. (\%) & 46 & 45 & 45 & 45 & 71 & 66 & 70 & 65 & 46 & 26 & 54 & 70 & 16 \\
\hline \multicolumn{14}{|c|}{ Total } \\
\hline 1989 & 254 & 58 & 113 & 119 & 184 & 27 & 85 & 155 & 257 & 113 & 72 & 82 & 1.519 \\
\hline 1990 & 185 & 133 & 151 & 129 & 227 & 170 & 125 & 83 & 204 & 303 & 272 & 104 & 2.086 \\
\hline 1991 & 122 & 10 & 50 & 94 & 65 & 151 & 72 & 86 & 64 & 245 & 105 & 222 & 1.286 \\
\hline 1993 & 157 & 155 & 105 & 80 & 40 & 55 & 301 & 19 & 151 & 103 & 89 & 0 & 1.255 \\
\hline 1994 & 52 & 322 & 89 & 141 & 146 & 84 & 180 & 20 & 71 & 179 & 121 & 70 & 1.473 \\
\hline 1995 & 57 & 162 & 43 & 32 & 14 & 144 & 52 & 67 & 119 & 130 & 51 & 135 & 1.005 \\
\hline 1996 & 291 & 144 & 160 & 63 & 9 & 144 & 118 & 193 & 129 & 68 & 73 & 119 & 1.510 \\
\hline 1997 & 389 & 183 & 43 & 26 & 63 & 108 & 143 & 130 & 137 & 290 & 206 & 150 & 1.866 \\
\hline 1998 & 125 & 260 & 190 & 257 & 112 & 80 & 145 & 203 & 237 & 119 & 43 & 159 & 1.930 \\
\hline Média & 181,3 & 158,6 & 104,9 & 104,6 & 95,6 & 107,0 & 135,7 & 106,2 & 152,1 & 172,2 & 114,7 & 115,7 & 1.549 \\
\hline Total & 1.632 & 1427 & 944 & 941 & 860 & 963 & 1.221 & 956 & 1.369 & 1.550 & 1.032 & 1.041 & 13.941 \\
\hline C.V. (\%) & 58 & 56 & 49 & 63 & 76 & 43 & 51 & 61 & 42 & 47 & 63 & 51 & 21 \\
\hline
\end{tabular}


caso de o sistema ser desenvolvido na ausência de práticas conservacionistas de suporte.

No mês de maio, por outro lado, ocorreu apenas $6 \%$ desse vol ume, caracterizando-se como o mês de menor risco de erosão hídrica.

Na primavera-verão, ocorreram 49 e $52 \%$ do número e volume, respectivamente, das chuvas erosivas, enquanto, para as chuvas não-erosivas, essa distribuição foi, respectivamente, de 57 e 60 \% em relação ao total, ind uindo outono-inverno (Quadro 3), concordando com Schick (1999) e Beutler (2000).

Assim, tanto o número quanto o volume das chuvas erosivas apresentaram distribuição sazonal relativamente uniforme, enquanto as chuvas nãoerosivas mostraram distribuição relativamente desuniforme. As chuvas não-erosivas apresentaram importância relativamente pequena, quando comparadas às erosivas, do ponto de vista da erosão hídrica. Assim, sua concentração na primaveraverão teve pouca importância. A distribuição relativamente uniforme do número e do volume das chuvas erosivas o ano todo, no entanto, dada a sua importância, possibilitou o risco de erosão hídrica semel hante em todas as estações, bem como o regular suprimento deágua pela chuva o ano todo na região. Todavia, considerando a erosividade das chuvas, o risco foi maior na primavera-verão.

\section{Erosividade das chuvas - fator $R$ da E UPS}

Em termos absolutos, o fator de erosividade EW, o qual é representado pela energia cinética total da chuva calculada pela equação de Wagner \& Massambani (1988), apresentou o mel hor coeficiente de correlação $(r=0,759)$ com as perdas de solo (Quadro 4). O teste de homogeneidade indicou, no entanto, que, com exceção dos fatores $\mathrm{EI}_{5}, \mathrm{EW}_{5}$, $\mathrm{EI}>25$ e $\mathrm{EW}>25$, os quais apresentaram os menores val ores der, os demais não diferiram entre si, concordando com Schick (1999) e Beutler (2000). Os baixos valores de $r$ dos fatores recém-referidos são explicados, provavelmente, pelo clima da região, o qual se parece mais com o temperado do que com o tropical e, por isso, as precipitações de elevada intensidade e curta duração são menos freqüentes do que em regiões de clima tipicamente tropical.

Quadro 3. Número e volume das chuvas erosi vas, não-erosi vas e total, observadas nas distintas estações do ano, no período de 1989 a 1998 em Lages (SC)

\begin{tabular}{|c|c|c|c|c|c|c|}
\hline \multirow{2}{*}{ Ano } & \multicolumn{2}{|c|}{ Erosivas } & \multicolumn{2}{|c|}{ Não-erosivas } & \multicolumn{2}{|c|}{ Total } \\
\hline & Número & Volume & Número & Volume & Número & Volume \\
\hline & & $\mathrm{mm}$ & & $\mathrm{mm}$ & & $\mathrm{mm}$ \\
\hline \multicolumn{7}{|c|}{ Primavera-verão } \\
\hline 1989 & 21 & 887 & 27 & 130 & 48 & 1.017 \\
\hline 1990 & 17 & 648 & 35 & 179 & 52 & 827 \\
\hline 1991 & 23 & 547 & 36 & 120 & 59 & 667 \\
\hline 1993 & 23 & 446 & 34 & 146 & 57 & 592 \\
\hline 1994 & 30 & 878 & 30 & 148 & 60 & 1.026 \\
\hline 1995 & 23 & 478 & 33 & 135 & 56 & 613 \\
\hline 1996 & 27 & 649 & 29 & 173 & 56 & 822 \\
\hline 1997 & 20 & 675 & 40 & 169 & 60 & 844 \\
\hline 1998 & 31 & 916 & 35 & 142 & 66 & 1.058 \\
\hline Média & 23,9 & 680,4 & 33,2 & 149,1 & 57,1 & 829,6 \\
\hline Total & 215 & 6.124 & 299 & 1.342 & 514 & 7.466 \\
\hline C.V. (\%) & 18 & 25 & 11 & 13 & 8 & 20 \\
\hline \multicolumn{7}{|c|}{ Outono-inverno } \\
\hline 1989 & 24 & 362 & 39 & 140 & 63 & 502 \\
\hline 1990 & 45 & 1.116 & 32 & 143 & 77 & 1.259 \\
\hline 1991 & 17 & 507 & 31 & 112 & 48 & 619 \\
\hline 1993 & 19 & 597 & 17 & 66 & 33 & 663 \\
\hline 1994 & 18 & 367 & 24 & 80 & 42 & 447 \\
\hline 1995 & 18 & 310 & 20 & 83 & 38 & 393 \\
\hline 1996 & 22 & 558 & 31 & 130 & 53 & 688 \\
\hline 1997 & 32 & 965 & 20 & 57 & 52 & 1.022 \\
\hline 1998 & 27 & 803 & 16 & 69 & 43 & 872 \\
\hline Média & 24,7 & 620,6 & 25,6 & 97,8 & 50,2 & 718,3 \\
\hline Total & 222 & 5.585 & 230 & 880 & 452 & 6.465 \\
\hline C.V. (\%) & 35 & 43 & 29 & 33 & 25 & 37 \\
\hline
\end{tabular}


Quadro 4. Valores do coeficiente de correlação ( $r$ ), obtidos entre os diversos fatores de erosividade das chuvas e as respectivas perdas de solo ocorridas na parcela-padrão da EUPS, no período de 1989 a 1998 em Lages (SC)

\begin{tabular}{|c|c|}
\hline Fator de erosividade & $\mathbf{r}$ \\
\hline 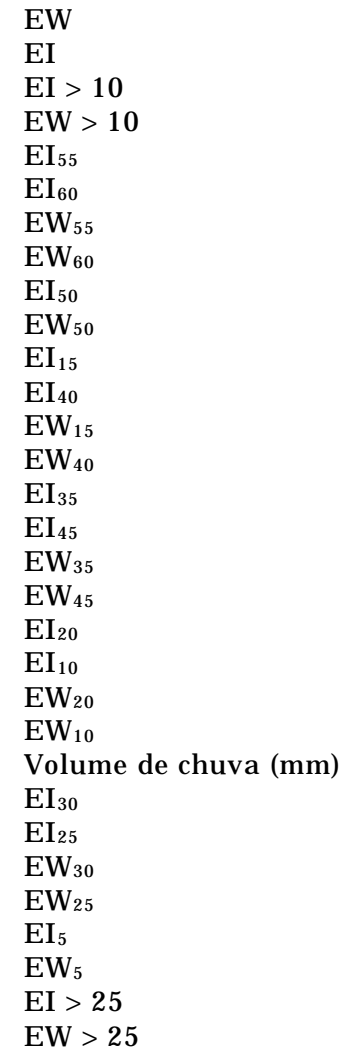 & $\begin{array}{l}0,759^{*} a \\
0,751^{*} a b c \\
0,746^{*} a b c \\
0,744^{*} a b c \\
0,740^{*} a b c \\
0,737^{*} a b c \\
0,735^{*} a b c \\
0,732^{*} a b c \\
0,730^{*} a b c \\
0,725^{*} a b c \\
0,723^{*} a b c \\
0,722^{*} a b c \\
0,717^{*} a b c \\
0,717^{*} a b c \\
0,711^{*} a b c \\
0,708^{*} a b c \\
0,703^{*} a b c \\
0,703^{*} a b c \\
0,70 *^{*} a b c \\
0,697^{*} a b c \\
0,694^{*} a b c \\
0,693^{*} a b c \\
0,692^{*} a b c \\
0,687^{*} a b c \\
0,684^{*} a b c \\
0,681^{*} a b c \\
0,678^{*} a b c \\
0,661^{*} b c \\
0,656^{*} c \\
0,481^{*} d \\
0,478^{*} d\end{array}$ \\
\hline
\end{tabular}

Valores seguidos de mesma letra não diferem pelo método de Steel \& Torrie (1960) a $5 \%$ de significância. * Significativo a $5 \%$ pelo teste t Student.

EI: fator de erosividade, segundo o método de Wischmeier \& Smith (1978).

EW: fator de erosividade, segundo o método de Wagner \& Massambani (1988).

Em geral, os fatores de erosividade das chuvas obtidos por meio da equação de Wagner \& Massambani (1988) foram iguais àqueles obtidos pela equação de Wischmeier \& Smith (1958) (Quadro 4), o que também foi verificado por outros autores (Carvalho et al., 1993; J acobs et al., 1994; Marques et al., 1997; Silva et al., 1997; Schick, 1999; Beutler, 2000). Portanto, os dois métodos podem ser utilizados para a obtenção do fator de erosividade para Lages (SC).

$\mathrm{O}$ fator de erosividade, $\mathrm{EI}_{30}$, obtido pelo método proposto por Wischmeier \& Smith (1958), é mundialmente reconhecido como ofator R da EUPS proposta por Wischmeier \& Smith (1978), sendo recomendado também para muitas regiões no Brasil (Lombardi Neto, 1977; Biscaia et al., 1981; Morais et al., 1988; Carvalho et al., 1989; Cantalice \& Margolis, 1993; Marques et al., 1997; Silva et al., 1997; Al buquerque et al., 1998; Schick, 1999; Beutler, 2000). Assim, diante da uniformidade estatística dos valores dos coeficientes de correlação obtidos entre os fatores de erosividade e as perdas de solo, podese recomendar o $\mathrm{El}_{30}$ como o fator de erosividade para a região de Lages (SC). Esta recomendação baseia-se, ainda, no fato de ser este fator mundialmente reconhecido e utilizado.

O valor do coeficiente de correlação $(r=0,687)$, encontrado no presente trabalho, por meio da correlação linear entre o $\mathrm{EI}_{30}$ e as perdas de solo da parcela-padrão da EUPS, foi menor do que os obtidos por Wischmeier (1959), para as condições dos EUA ( $r=0,84$ a 0,98), e por alguns autores, para o Brasil (Marques et al., 1997) ( $r=0,87$ e 0,72), (Biscaia et al., 1981) ( $r=0,77$ e 0,72) e(Al buquerque et al., 1998) $(r=0,734)$. No entanto, foi superior aos encontrados por Lombardi N eto (1977) $(r=0,67)$, Morais (1986) $(r=0,57$ e 0,66$)$ e Beutler (2000) $(r=0,350)$ e praticamente igual aos obtidos por Bertol \& Miquelluti (1993) ( $r=0,697)$ eSchick (1999) ( $r=0,687)$, para esse mesmo local.

\section{Fator de erosividade, $\mathrm{EI}_{30}$ - distribuição}

O fator de erosividade médio anual, expresso pelo $\mathrm{EI}_{30}$, foi de 5.790 MJ mm ha-1 $\mathrm{h}^{-1}$ (Quadro 5), enquadrando-se na faixa de valores de 5.000 a $12.000 \mathrm{MJ} \mathrm{mm} \mathrm{ha-1} \mathrm{h}^{-1}$ que, normal mente, ocorre no Brasil (Cogo, 1988). E ste val or é semel hante ao encontrado para o mesmo local, num período de 10 anos, por Bertol (1993) (5.694 MJ mm ha-1 $\mathrm{h}^{-1}$ ) e, num período seis anos, por Schick (1999) (5.541 MJ mm ha-1 $\left.\mathrm{h}^{-1}\right)$, e, ainda, para al guns locais do Paraná, por Rufino (1986) (5.275 MJ mm ha-1 $\mathrm{h}^{-1}$ ).

Por outro lado, o valor do $\mathrm{EI}_{30}$ encontrado neste trabalho foi maior do que o valor encontrado por Margolis et al. (1985), para Caruaru (PE) (2.100 MJ mm ha-1 $\left.\mathrm{h}^{-1}\right)$, enquanto, para outras regiões do Brasil, foi menor, tais como: $12.559 \mathrm{MJ} \mathrm{mm} \mathrm{ha}^{-1} \mathrm{~h}^{-1}$, para al guns locais do Paraná

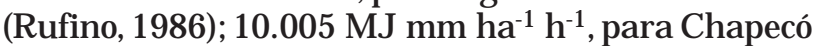
(SC) (Beutler, 2000); $8.355 \mathrm{MJ} \mathrm{mm} \mathrm{ha}^{-1} \mathrm{~h}^{-1}$, para Goiânia (GO) (Silva et al., 1997), e 7.747 MJ mm ha-1 $\mathrm{h}^{-1}$, para Mococa (SP) (Carval ho et al., 1989). A grande variabilidade espacial do fator de erosividade no Brasil é natural, decorrente da variabilidade dimática entreas diversas regi ões do País, indicando grande variabilidade no risco de erosão hídrica.

Os valores médios mensais dofator $\mathrm{EI}_{30}$ variaram amplamente, bem como os anuais, alcançando valores de zero (em al guns meses de determinados anos) a 2.783 MJ mm ha-1 $\mathrm{h}^{-1}$ (em fevereiro de 1997), com os maiores valores concentrando-se, principal mente, no intervalo entre setembro e março, e os menores, entre abril e agosto (Quadro 5), o que 
originou os altos valores de coeficiente de variação. Isto é explicado pela variabilidade climática temporal, a qual é normal, indicando que, em determinados períodos do ano, em média, os riscos na erosão hídrica nessa região são maiores do que em outros. A grande variabilidadetemporal do fator $\mathrm{EI}_{30}$ influencia fortemente a predição das perdas de solo pelo modelo EUPS, uma vez que esse fator representa, no referido model o, o fator $\mathrm{R}$.

Nas regiões do País onde as estações do ano diferenciam-se entre si em relação ao clima, como é o caso de Lages e Chapecó (SC), por exemplo, é de se esperar que as erosividades das chuvas também se diferenciem. Em média, o $\mathrm{EI}_{30}$ anual foi cerca de $74 \%$ maior na primavera-verão do que no outonoinverno (Quadro 6), diferindo do comportamento encontrado por Schick (1999), que trabalhou com dados de seis anos para o mesmo local, e de Beutler (2000), que trabalhou com dados de seis anos para Chapecó(SC), nos quais o $\mathrm{EI}_{30}$ foi cerca de duas vezes mai or na primavera-verão do queno outono-inverno.
Essa diferença, no caso do trabalho de Schick, para Lages, éexplicada pela diferença no período de tempo de coleta de dados e, no caso do trabal ho de Beutler, para Chapecó, por este fator e, principalmente, pela diferença de padrão climático entre as duas regiões. Estes dados indicam que o risco de erosão hídrica na região de Lages é substancialmente maior na primavera-verão do que no outono-inverno, visto que muitas ár eas são ainda cultivadas sob o sistema de preparo convencional nessa época do ano na região. Do mesmo modo que no caso da distribuição temporal, e pela mesma razão, a distribuição espacial do fator $\mathrm{EI}_{30}$ também influencia a predição das perdas de sol o pelo modelo EUPS.

O conhecimento da distribuição média mensal da erosividade de determinado local é de fundamental importância prática, pois fornece subsídio ao planejamento conservacionista do sol o, com atenção especial aos períodos do ano em que ocorrem erosividades críticas.

Quadro 5. Valores mensais, anuais e médios mensais do fator de erosividade, $\mathrm{EI}_{30}$, obtidos no período de 1989 a 1998 em Lages (SC)

\begin{tabular}{|c|c|c|c|c|c|c|c|c|c|c|c|c|c|}
\hline Ano & J an. & Fev. & Mar. & Abr. & Maio & J un. & J ul. & Ago. & Set. & Out. & Nov. & Dez. & Total \\
\hline & \multicolumn{13}{|c|}{ If $m m ~ h a^{-1} h^{-1}$} \\
\hline 1989 & 625 & 376 & 663 & 588 & 632 & 8 & 15 & 521 & 546 & 227 & 63 & 194 & 4.458 \\
\hline 1990 & 502 & 494 & 751 & 324 & 527 & 235 & 323 & 30 & 762 & 1.181 & 1.873 & 537 & 7.539 \\
\hline 1991 & 622 & 0 & 188 & 187 & 14 & 137 & 123 & 141 & 712 & 1.139 & 667 & 680 & 4.610 \\
\hline 1993 & 613 & 1.102 & 455 & 179 & 23 & 124 & 1377 & 48 & 350 & 286 & 600 & 0 & 5.157 \\
\hline 1994 & 298 & 1.398 & 650 & 638 & 441 & 321 & 415 & 0 & 51 & 676 & 344 & 314 & 5.546 \\
\hline 1995 & 134 & 730 & 52 & 41 & 0 & 292 & 64 & 53 & 445 & 155 & 31 & 993 & 2.990 \\
\hline 1996 & 1.514 & 1.076 & 1.580 & 237 & 0 & 279 & 214 & 395 & 192 & 802 & 176 & 190 & 6.655 \\
\hline 1997 & 2.783 & 965 & 48 & 0 & 81 & 398 & 224 & 265 & 699 & 1.041 & 781 & 746 & 8.031 \\
\hline 1998 & 639 & 1.575 & 793 & 1.201 & 218 & 93 & 370 & 565 & 575 & 301 & 296 & 494 & 7.120 \\
\hline Média & 858,9 & 807,3 & 575,6 & 377,2 & 215,1 & 209,7 & 347,2 & 224,2 & 481,3 & 645,3 & 536,8 & 460,9 & $5.789,5$ \\
\hline C.V. (\%) & 90 & 56 & 78 & 95 & 111 & 57 & 111 & 93 & 48 & 61 & 100 & 65 & 27 \\
\hline
\end{tabular}

Quadro 6. Valores médios estacionais do fator de erosividade, $\mathrm{EI}_{30}$, obti dos no período de 1989 a $1998 \mathrm{em}$ Lages (SC)

\begin{tabular}{|c|c|c|c|c|c|c|c|c|c|c|}
\hline \multirow{2}{*}{ E stação do ano } & \multicolumn{9}{|c|}{ Ano } & \multirow{2}{*}{ Média } \\
\hline & 1989 & 1990 & 1991 & 1993 & 1994 & 1995 & 1996 & 1997 & 1998 & \\
\hline & \multicolumn{9}{|c|}{ - MJ $\mathrm{mm} \mathrm{ha}^{-1} \mathrm{~h}^{-1}$} & \\
\hline $\begin{array}{l}\text { Primavera-verão } \\
\text { Outono-inverno }\end{array}$ & $\begin{array}{l}3.086 \\
1.372\end{array}$ & $\begin{array}{l}3.629 \\
3.910\end{array}$ & $\begin{array}{l}3.089 \\
1.521\end{array}$ & $\begin{array}{l}2.354 \\
2.803\end{array}$ & $\begin{array}{l}4.338 \\
1.208\end{array}$ & $\begin{array}{l}1.719 \\
1.271\end{array}$ & $\begin{array}{l}5.235 \\
1.420\end{array}$ & $\begin{array}{l}4.725 \\
3.306\end{array}$ & $\begin{array}{l}4.886 \\
2.234\end{array}$ & $\begin{array}{l}3.673,4 \\
2.116,1\end{array}$ \\
\hline Total & 4.458 & 7.539 & 4.610 & 5.157 & 5.546 & 2.990 & 6.655 & 8.031 & 7.120 & $5.789,5$ \\
\hline
\end{tabular}


Do ponto de vista científico, a obtenção do fator de erosividade permite cal cular o fator de erodibilidade.

Anal isando os dados obti dos no trabal ho, verificase que o período de setembro a março, com $76 \%$ da erosividade média anual (Quadro 5 e Figura 1), caracteriza-se como a época crítica, com maior risco de erosão hídrica em Lages. Estes dados concordam parcialmente com aqueles encontrados por Eltz (1977), Saraiva (1978), Bertol (1993), Schwarz (1997), Schick (1999) e Beutler (2000). Neste período, os meses mais críticos, outubro, janeiro e fevereiro, apresentaram $41 \%$ da erosividade média anual, principalmente porque, em alguns anos durante o período experimental, tais meses registraram erosividades maiores do que $500 \mathrm{MJ} \mathrm{mm} \mathrm{ha}^{-1} \mathrm{~h}^{-1}$, val or este considerado crítico por Rufino (1986).

Este problema acentua-se sobretudo porque, em setembro/outubro, o solo é preparado no sistema de manejo convencional (sistema ainda comum na região), e as culturas de primavera/verão são semeadas, o que deixa o sol o susceptível à erosividade das chuvas.

No sistema de semeadura direta, por outrolado, apesar da presença de resíduos vegetais na superfície do solo, a semeadura das culturas é feita em linhas retas, sem o necessário contorno no declive, dada a ausência de práticas conservacionistas de suporte, como o terraceamento, por exemplo, o quetorna esse sistema também susceptível à erosão hídrica na região, nessa época do ano.

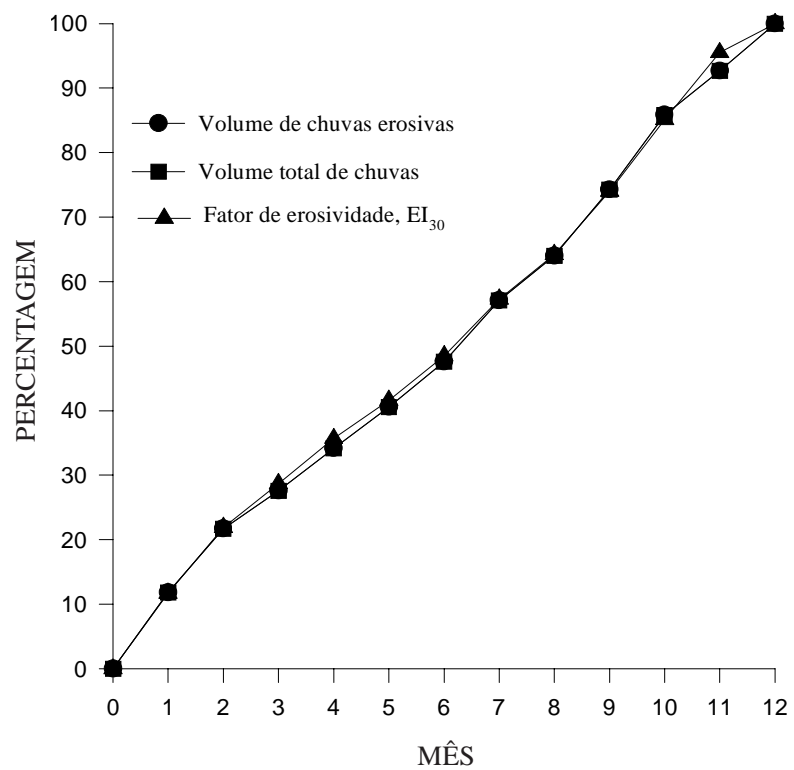

Figura 1. Curvas de distribuição do volume das chuvas erosivas e total e do fator de erosi vidade, $\mathrm{EI}_{30}$, obtidos no período de 1989 a $1998 \mathrm{em}$ Lages (SC). (Os meses 0, 1, 2, 3, 4, 5, 6, 7, $8,9,10$, 11 e 12 equivalem às datas $1 /$ jan., $1 /$ fev., 1/mar., 1/abr., 1/maio, 1/jun., 1/jul., 1/ago., 1/set., 1/out., 1/nov., 1/dez e 1/jan., respectivamente).
O período restante do ano, abril a agosto, com $34 \%$ da erosividade média anual, apresenta menor risco de erosão, considerando, ainda, que, na quase totalidade desses meses, ovalor do $\mathrm{EI}_{30}$ esteve abaixo do val or mensal de $500 \mathrm{MJ} \mathrm{mm} \mathrm{ha}^{-1} \mathrm{~h}^{-1}$, considerado crítico por Rufino (1986). Desse modo, pela figura 1, podem-se distinguir duas épocas anuais distintas, em termos de erosividade das chuvas, em Lages (SC).

\section{CONCLUSÕES}

1. O fator de erosividade (fator R da EUPS) recomendado para Lages (SC), para predizer as perdas de solo, é o $\mathrm{EI}_{30}$.

2. O fator deerosividademédioanual, $\mathrm{EI}_{30}$ (fator $\mathrm{R}$ da EUPS), para Lages (SC) éde5.790 MJ $\mathrm{mm} \mathrm{ha}^{-1} \mathrm{~h}^{-1}$; $63 \%$ doEl 30 ocorrena primavera-verão, concentrando $76 \%$ no período de setembro a março e, em outubro, janeiro e fevereiro, $41 \%$ do referido fator.

3. Em média, $45 \%$ do número e $84 \%$ do volume das chuvas de Lages (SC) são erosivas; dentre as chuvas erosivas, $49 \%$ do número e $52 \%$ do volume ocorrem na primavera-verão.

\section{AGRADE CIME NTO}

Aos acadêmicos do Curso de Agronomia do CAV/ UDESC, J armum Marcelos Massariol, Émerson Fábio dos Reis e Leonir Dily, pelo auxílio na coleta dos dados no campo eseu tratamento nolaboratório.

\section{LITERATURA CITADA}

ALBUQUERQUE, A.W.; LOMBARDI NETO, F.; CATANEO, A. \& SRINIVASAN, V.S. Parâmetros erosividade da chuva e da enxurrada correlacionados com as perdas de solo de um solo bruno não-cálcico vértico em Sumé (PB). R. Bras. Ci. Solo, 22:743-749, 1998.

BERTOL, I. Índice de erosividade $\left(\mathrm{EI}_{30}\right)$ para Lages (SC) - 1a aproximação. Pesq. Agropec. Bras., 28:515-521, 1993.

BERTOL, I. Avaliação da erosividade da chuva na localidade de Campos Novos (SC) no período de 1981-1990. Pesq. Agropec. Bras., 29:1453-1458, 1994.

BERTOL, I. \& MIQUELLUTI, D.J. Perdas de solo, água e nutrientes reduzidas pela cultura do milho. Pesq. Agropec. Bras., 28:1205-1213, 1993.

BEUTLER, J.F. Erosão hídrica num Latossolo Vermel ho aluminoférrico submetido a diferentes sistemas de preparo e cultivo do solo. Lages, Universidade do Estado de Santa Catarina, 2000. 105p. (Tese de Mestrado)

BISCAIA, R.C.M.; RUFINO, R.L. \& HENKLAIN, J.C. Cálculo de erodibilidade (Fator K) de dois sol os do Estado do Paraná. R. Bras. Ci. Solo, 5:183-186, 1981. 
CANTALICE, J.R.B. \& MARGOLIS, E. Características das chuvas e correlação de índices de erosividade com as perdas de solo do Agreste de Pernambuco. R. Bras. Ci. Solo, 17:275-281, 1993.

CARVALHO, M.P.; CATANEO, A. \& LOMBARDI NETO, F. índices de erosividade da chuva e enxurrada correlacionados com as perdas de solo e determinação da erodibilidade de um Latossolo Roxo distrófico de Campinas (SP). R. Bras. Ci. Solo, 17:445-450, 1993.

CARVALHO, M.P.; CATANEO, A. \& LOMBARDI NETO, F. Parâmetros de erosividade da chuva e da enxurrada correlacionados com as perdas de solo e determinação da erodibilidade de um podzólico vermelho-amarelo de Pindorama. R. Bras. Ci. Solo, 21:279-286, 1997.

CARVALHO, M.P.; LOMBARDI NETO, F.; VASQUES FILHO, J. \& CATANEO A. Índices de erosividade da chuva correlacionados com as perdas de um podzólico vermel hoamarel o eutrófico textura argilosa/muito argilosa de Mococa (SP): primeira aproximação do fator erodibilidade. R. Bras. Ci. Solo, 13:237-242, 1989.

CATANEO, A.; CASTRO FILHO, C. \& ACQUAROLE, R.M. Programa para cál culo deíndices de erosividade de chuvas. R. Bras. Ci. Solo, 6:236-239, 1982.

COGO, N.P. Uma contribuição à metodologia de estudo das perdas de erosão em condições de chuva natural. I. Sugestões gerais, medição dos volumes, amostragem e quantificação de sol o eágua da enxurrada (1a aproximação). In: ENCONTRO NACIONAL DE PESQUISA SOBRE CONSERVAÇÃO DO SOLO, 2., Passo Fundo, 1978. Anais. Passo F undo, Empresa Brasileira de Pesquisa Agropecuária, 1978. p.75-98.

COGO, N.P. Conceitos e princípios científicos envolvidos no manejo de solo para fins de controle da erosão hídrica. In: CONGRESSO BRASILEIRO DE CIÊNCIA DO SOLO, 21., Campinas, 1988. Anais. Campinas, Sociedade Brasileira de Ciência do Solo, 1988. p.251-262.

ELTZ, F.L.F. Perdas por erosão sob precipitação natural em diferentes manejos de solo e coberturas vegetais. I. Solo da unidade de mapeamento SãoJ erônimo - primeira etapa experimental. Porto Alegre, Universidade Federal do Rio Grande do Sul, 1977. 97p. (Tese de Mestrado)

FOSTER, G.R.; MCCOOL, D.K.; RENARD, K.E. \& MOLDENHAUER, W.C. Conversion of the universal soil Ioss equation toSI metric units. Soil Water Conserv., 36:355359, 1981.

GRAYBILL, F.A. An introdution to linear statistical models. New York, McGraw Hill, 1961. 684p.

HUDSON, N.W. Soil conservation. 2.ed. Ithaca, Cornell University Press, 1981. 324p.

J ACOBS, G.A.; ROLLOF, G.; BISCAIA, R.C.M. \& MERTEN, G. Erosividade da chuva correlacionada com perdas de solo de dois Latossolos Vermelho-Escuros (textura argilosa e média): uma aproximação do fator erodibilidade do solo. In: REUNIÃO BRASILEIRA DE MANEJO E CONSERVAÇÃO DO SOLO E DA ÁGUA, 10., Florianópolis, 1994. Anais. Florianópolis, Sociedade Brasileira de Ciência do Solo, 1994. p.170-171.

J ESUS FILHO, J.D. Manejo de solos de encostas basálticas e suas relações com a erosão hídrica. Porto Alegre, Universidade Federal do Rio Grande do Sul, 1987. 93p. (Tese de Mestrado)
LAL, R.; LAWSON,T.L. \& ANASTASE, A.H. Erosivity of tropical rains. In: BOODT, M. \& GABRIELS, D., eds. assessment of erosion. Chichester, J ohn \& Wiley, 1980. p.143-151.

LOMBARDI NETO, F. Rainfall erosivity - its distribution and relationship with soil loss at Campinas, Brazil. West Lafayette, PurdueUniversity, 1977. 53p. (Tese de Mestrado)

MARIA, I.C. Cálculo da erosividade da chuva. In: LOMBARDI NETO, F.; CASTRO, O.M.; DECHEN, S.C.F.; VIEIRA, S.R. \& MARIA, I.C. Manual de programas de processamento de dados de campo e de laboratório para fins de experimentação em conservação do solo. Campinas, Instituto Agronômico de Campinas, 1994. não paginada.

MARGOLIS, E.; SILVA, A.B. \& J ACQUES, F.O. Determinação dos fatores da equação universal de perdas de solo para as condições de Caruaru (PE). R. Bras. Ci. Solo, 9:165-169,1985.

MARQUES, J.J.G.S.M.; ALVARENGA, R.C.; CURI, N.; SANTANA, D.P. \& SILVA, M.L.N. Índices de erosividade da chuva, perdas de solo e erodibilidade para dois sol os da região dos cerrados - primeira aproximação. R. Bras. Ci. Solo, 21:427-434, 1997.

MORAIS, L.F.B.; MUTTI, L.S.M. \& ELTZ, F.L.F. Índices de erosividade correlacionados com perdas de solo no Rio Grande do Sul. R. Bras. Ci. Solo, 12:281-284, 1988.

RUFINO, R.L. Avaliação do potencial erosivo da chuva para o Estado do Paraná: segunda aproximação. R. Bras. Ci. Solo, 10:279-281, 1986.

SARAIVA, O.F. Perdas por erosão sob precipitação natural em diferentes manejos de solo e coberturas vegetais. I. Solo da unidade de mapeamento São J erônimo - 2a etapa experimental. Porto Alegre, Universidade Federal do Rio Grande do Sul, 1978. 126p. (Tese de Mestrado)

SCHWARZ, R.A. Perdas por erosão hídrica em diferentes classes de declividade, sistemas de preparo e níveis de fertilidade do solo na região das Missões - RS. Porto Alegre, Universidade Federal do Rio Grande do Sul, 1997. 130p. (Tese de Mestrado)

SCHICK, J. Erosão hídrica em Cambissolo Húmico álico submetido a diferentes sistemas de preparo e cultivo do solo. Lages, Universidade do Estado de Santa Catarina, 1999. 114p. (Tese de Mestrado)

SILVA, M.L.N.; FREITAS, P.L.; BLANCANEAUX, P.; CURI, N. \& LIMA, J .M. Relação entre parâmetros da chuva e perdas de solo e determinação da erodibilidade de um Latossolo Vermelho-escuro em Goiânia (GO). R. Bras. Ci. Solo, 21:131-137, 1997.

STEEL, R.G.D. \& TORRIE, J.H. Principles and procedures of statistics. New York: McGraw-Hill Book Company, 1960. 481p.

WAGNER, C.S. \& MASSAMBANI, O. Análise da relação intensidade da chuva-energia de Wischmeier \& Smith e sua aplicabilidade à região de São Paulo. R. Bras. Ci. Solo, 12:197-203, 1988.

WISCHMEIER, W.H. A rainfall erosion index for a universal soil loss equation. Soil Sci. Soc. Am. Proc., 23:246-249, 1959.

WISCHMEIER, W.H. \& SMITH, D.D. Rainfall energy and its relationship to soil loss. Trans. Am. Geophys. Union, 39:285-291, 1958.

WISCHMEIER, W.H. \& SMITH, D.D. Predicting rainfall erosion Iosses: a guide to conservation planning. Washington, United States Departament of Agriculture, 1978. 58p. (Agriculture Handbook, 537) 